\title{
SUPRESSÃo Imposta PElo Mesotrione a Brachiaria brizantha EM Sistema de INTEGRAÇÃo LAVOURA-PECUÁRIA ${ }^{1}$
}

\author{
Suppression Imposed by Mesotrione to Brachiaria brizantha in Crop-Livestock System
}

\author{
DAN, H.A. ${ }^{2}$, BARROSO, A.L.L. ${ }^{3}$, DAN, L.G.M. ${ }^{4}$, PROCÓPIO, S.O. ${ }^{5}$, OLIVEIRA JR., R.S. ${ }^{6}$, \\ CONSTANTIN, $\mathrm{J} .{ }^{6}$ e FELDKIRCHER, C. ${ }^{7}$
}

\begin{abstract}
RESUMO - Mesotrione é um importante herbicida registrado para uso na cultura do milho, porém pouco tem sido feito para estudar a suscetibilidade de espécies como Brachiaria brizantha a esse herbicida. O presente trabalho teve por objetivo avaliar a supressão imposta pelo mesotrione em plantas de Brachiaria brizantha, visando à viabilização de um cultivo integrado com a cultura do milho. Os tratamentos foram distribuidos em blocos casualizados, com quatro repetições, sendo estes constituidos por sete doses de mesotrione $(0,12,24,48,96$, 144 e $192 \mathrm{~g} \mathrm{ha}^{-1}$ ), um tratamento com o cultivo de milho solteiro e capinado, além de um tratamento com capim-braquiária cultivado de forma solteira e capinada, totalizando assim nove tratamentos. As espécies milho e B. brizantha (cv. Marandu) foram semeadas concomitantemente. Os tratamentos herbicidas foram aplicados aos 20 dias após a emergência das espécies. O mesotrione mostrou maior potencial de fitointoxicação em plantas de $B$. brizantha ao ser aplicado na dose de $192 \mathrm{~g} \mathrm{ha}^{-1}$. Entretanto, a espécie forrageira apresentou tolerância satisfatória ao herbicida, demonstrando potencial de utilização no sistema de integração lavoura-pecuária. A competição interespecífica proporcionou reduções no rendimento do milho, e a melhor relação dose-beneficio para esse sistema foi obtida com a utilização de $96 \mathrm{~g} \mathrm{ha}^{-1}$ de mesotrione.
\end{abstract}

Palavras-chave: consorciação, inibidores da HPPD, Poaceae, milho, Zea mays.

\begin{abstract}
Mesotrione is an important herbicide applied to corn, but little is known about the susceptibility of species, such as Brachiaria brizantha to this herbicide. The objective of this study was to evaluate the suppression imposed by mesotrione in Brachiaria brizantha, intercropped with maize. The trial was conducted in a randomized block design with four replications, corresponding to seven doses of mesotrione (0; 12; 24; 48; 96; 144 and $192 \mathrm{~g} \mathrm{ha}^{-1}$ ), a control (corn without interference) and a treatment with beard grass grown as a single. Both crops were sown on the same day. The herbicide was applied at 20 days after emergence of the species. Mesotrione showed the greatest potential for plant toxicity in $\boldsymbol{B}$. brizantha plants, when applied at a dose of $192 \mathrm{~g} \mathrm{ha}^{-1}$. However, grass forage showed satisfactory tolerance to the herbicide, indicating potential use in crop-livestock systems. The inter-specific competition led to reductions in corn yield, and the best dose-response relationship to benefit both cultures was obtained by using $96 \mathrm{~g} \mathrm{ha-1} \mathrm{of} \mathrm{mesotrione.}$
\end{abstract}

Keywords: intercropping, HPPD-inhibitors, Poaceae, corn, Zea mays.

\section{INTRODUÇÃO}

Brachiaria brizantha é considerada uma excelente forrageira tropical e tem sido utilizada como uma das principais espécies que compõem o sistema de integração lavourapecuária. Sua implantação tem visado tanto à formação de pastagens para a alimentação animal (Macedo, 2009) quanto à formação de palhada para o sistema de plantio direto,

Recebido para publicação em 3.3.2011 e aprovado em 25.4.2011.

2 Doutorando, Programa de Pós-Graduação em Agronomia, Universidade Estadual de Maringá - UEM/NAPD, Av. Colombo 5790, 87020-900 Maringá-PR, <halmeidadan@gmail.com>; ${ }^{3}$ Professor da Faculdade de Agronomia, Universidade de Rio Verde - FESURV, 75900-000 Rio Verde-GO; ${ }^{4}$ Mestranda, Programa de Pós-Graduação em Agronomia, UEM/NUPAGRI; ${ }^{5}$ Pesquisador, Embrapa Soja, 86001-970 Londrina-PR; ${ }^{6}$ Professores do Dep. de Agronomia, UEM/NAPD; ${ }^{7}$ Graduando(a) em Agronomia, FESURV. 
garantindo assim maior sustentabilidade ao ambiente (Torres et al., 2008; Machado et al., 2010).

Pela rusticidade e tolerância ao inverno seco, $B$. brizantha possui maior expressão de cultivo na segunda safra ou safrinha, principalmente em sucessão à cultura da soja, podendo ser semeada tanto em semeadura direta quanto em sobressemeadura (Pacheco et al., 2008). Entretanto, essa espécie tem sido intensamente utilizada em consórcio com a cultura do milho, podendo ser semeada concomitante ou posteriormente à emergência da cultura (Jakelaitis et al., 2005). Segundo Portes et al. (2000), o sombreamento exercido pelo milho altera o crescimento, o perfilhamento e o rendimento forrageiro de $B$. brizantha; contudo, após a colheita do milho a forrageira se estabelece rapidamente, garantindo a formação antecipada da pastagem.

$\mathrm{O}$ fato de duas espécies germinarem e emergirem ao mesmo tempo pode, em algumas situações, gerar competição interespecífica, ocasionado significativas reduções no potencial produtivo da cultura principal (Jakelaitis et al., 2005, 2006); no caso da integração lavoura-pecuária, a cultura mais explorada vem sendo o milho. Nessas situações, é necessário o uso de herbicidas em subdoses, no intuito de regular o crescimento da forrageira e, com isso, assegurar o bom rendimento da cultura do milho, sem, no entanto, eliminar a espécie forrageira (Ferreira et al., 2007).

De modo geral, o atrazine e o nicosulfuron são os herbicidas mais utilizados no manejo de plantas daninhas na cultura do milho (Timossi, 2009). Entretanto, somente o nicosulfuron em subdoses apresenta efeito regulador sobre o crescimento de $B$. brizantha (Jakelaitis et al., 2005). Objetivando a supressão de $B$. brizantha em consórcio com o milho, Freitas et al. (2005) e Ferreira et al. (2007) constataram que o intervalo de dose adequado para esse sistema varia de 4 a $12 \mathrm{~g} \mathrm{ha}^{-1}$ de nicosulfuron. Por outro lado, a utilização de subdoses apresenta controle reduzido das espécies daninhas, com destaque para integrantes da família Poaceae.

Entre os herbicidas de ação graminicida e latifolicida com potencial para utilização em pós-emergência na cultura do milho, destacam-se os inibidores de carotenoides, principalmente os que inibem a enzima (4-hidroxifenil-piruvato-dioxigenase) (HPPD) (Felix \& Doohan, 2005). Esses herbicidas promovem branqueamento nas folhas, resultado da degradação oxidativa da clorofila e da membrana plasmática, gerando extravasamento do conteúdo celular, o que causa a necrose dos tecidos (Mitchell et al., 2001; Grossmann \& Ehrhardt, 2007).

O herbicida mesotrione - lançado recentemente no Brasil para uso em pós-emergência na cultura do milho - tem apresentado desempenho satisfatório no controle de plantas daninhas, sobretudo de gramineas. Todavia, poucos são os estudos referentes ao potencial de utilização desse herbicida em sistemas consorciados.

Para que o sistema de integração lavourapecuária continue se expandindo em nosso país, é de fundamental importância a identificação de herbicidas de aplicação em pós-emergência com ação sobre gramíneas, que apresentem seletividade ao milho e, simultaneamente, auxiliem no manejo de forrageiras consorciadas. Nesse contexto, o objetivo do presente trabalho foi avaliar a supressão imposta pelo mesotrione em plantas de Brachiaria brizantha, visando à viabilização de um cultivo integrado com a cultura do milho.

\section{MATERIAL E MÉTODOS}

O experimento foi conduzido durante a safra 2007/2008, no município de Rio VerdeGO, cujas coordenadas geográficas são: latitude de $17^{\circ} 47^{\prime} 24^{\prime \prime} \mathrm{S}$, longitude de $50^{\circ} 56^{\prime} 31^{\prime \prime} \mathrm{W}$ e altitude de 698 metros acima do nivel do mar. O clima regional, classificado pelo sistema internacional de Köppen, é do tipo CWA, úmido e inverno seco, com precipitação média anual de $1.500 \mathrm{~mm}$ e temperatura média anual de $25^{\circ} \mathrm{C}$.

O solo da área experimental é classificado como Latossolo Vermelho distroférrico, possuindo $450 \mathrm{~g} \mathrm{~kg}^{-1}$ de argila, $60 \mathrm{~g} \mathrm{~kg}^{-1}$ de silte e $490 \mathrm{~g} \mathrm{~kg}^{-1}$ de areia, com saturação por bases de $53 \%$ no momento do cultivo.

Antes da semeadura do milho, que ocorreu logo após a colheita da soja, a área foi manejada com $1.440 \mathrm{~g} \mathrm{ha}^{-1}$ de glyphosate. 
O cultivar de milho DKB 789 foi semeado no espaçamento de $0,5 \mathrm{~m}$ de forma mecanizada, obtendo-se uma população final de 53 mil plantas ha-1 ${ }^{-1}$ No momento da semeadura, realizou-se uma adubação de fundação com $250 \mathrm{~kg} \mathrm{ha}^{-1}$ da formulação 08-28-16 e, aos 15 dias após a emergência das plântulas, uma adubação de cobertura com $50 \mathrm{~kg} \mathrm{ha}^{-1}$ de nitrogênio.

As parcelas foram dimensionadas numa área de $21 \mathrm{~m}^{2}$ e os tratamentos distribuídos em blocos casualizados, com quatro repetições, sendo estes constituídos por sete doses de mesotrione (Callisto $\left.{ }^{\circledR}\right)(0,12,24,48,96,144$ e 192 g de i.a. ha ${ }^{-1}$ ), aplicadas aos 20 dias após a emergência do milho, um tratamento com o cultivo de milho solteiro e capinado, além de um tratamento com capim-braquiária cultivado de forma solteira e capinada.

A aplicação do mesotrione foi feita utilizando-se um pulverizador costal com pressurização por $\mathrm{CO}_{2}$, munido de barra de $2,5 \mathrm{~m}$, contendo seis pontas de pulverização do tipo TT 110-02, espaçados entre si de $0,5 \mathrm{~m}$, aplicando volume de calda equivalente a $150 \mathrm{~L} \mathrm{ha}^{-1}$. As condições ambientais no momento das aplicações eram de temperatura média de $27,2^{\circ} \mathrm{C}$, UR média de $74 \%$ e velocidade média do vento de $2,1 \mathrm{~km} \mathrm{~h}^{-1}$.

Brachiaria brizantha (cv. Marandu) foi semeada a lanço em área total de forma mecanizada, algumas horas antes da semeadura do milho, sendo usados, aproximadamente, $10 \mathrm{~kg} \mathrm{ha}^{-1}$ de sementes com valor cultural de $70 \%$.

As avaliações de intoxicação em $B$. brizantha foram realizadas aos 7 e 28 dias após a aplicação dos tratamentos (DAA), utilizando-se escala percentual de 0 a $100 \%$, em que 0 representou ausência de sintomas e 100 a morte de todas as plantas. Determinaram-se ainda os percentuais de controle das espécies invasoras Digitaria horizontalis e Cenchrus echinatus aos 28 DAA.

Aos 28 DAA e ao final do ciclo da cultura do milho, determinou-se o acúmulo de biomassa seca da parte aérea das plantas de $B$. brizantha. Para isso, foram coletadas amostras em $1 \mathrm{~m}^{2}$, em cada parcela, sendo esse material seco em estufa com circulação forçada de ar a $65^{\circ} \mathrm{C}$ durante 72 horas e imediatamente pesado em balança analítica. Foram determinadas ainda a altura das plantas de milho e a altura da inserção da primeira espiga, utilizando-se uma trena graduada, sendo referenciada a distância do colo da planta à extremidade final do pendão e da primeira espiga, respectivamente. A produtividade de grãos de milho foi determinada através da colheita manual das espigas das plantas presentes na área útil da parcela $\left(10 \mathrm{~m}^{2}\right)$; logo após a colheita, o material foi trilhado, pesado e a umidade dos grãos corrigida para $13 \%$, seguindo padrões recomendados para a cultura.

Os resultados foram submetidos à análise de variância, que foi realizada com o programa estatístico Sisvar $(\mathrm{p} \geq 0,05)$. Foram ajustados modelos lineares de regressão para as variáveis fitointoxicação e biomassa seca da forrageira (28 DAA) e controle das plantas invasoras. Para confecção das curvas de regressão empregando o programa Sigma Plot versão 10.0 e para as demais variáveis, procedeu-se às comparações das médias, utilizando o critério de agrupamento de Scott-Knott a 5\% de probabilidade.

\section{RESULTADOS E DISCUSSÃO}

Os niveis de fitointoxicação de $B$. brizantha em integração com o milho aumentaram linearmente com os incrementos das doses de mesotrione (Figura 1).

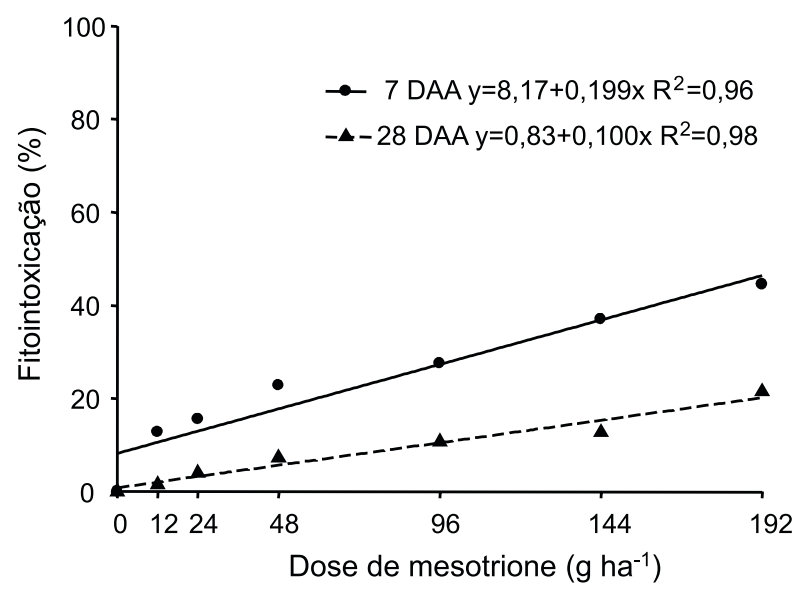

Figura 1 - Fitointoxicação apresentada por plantas de B. brizantha cultivada em integração com milho, aos 7 e 28 dias após a aplicação de diferentes doses de mesotrione em pós-emergência. 
Aos sete dias após a aplicação (DAA), foi observado que o nivel máximo de fitointoxicação apresentado pela forrageira foi de $46,3 \%$, para a dose de $192 \mathrm{~g} \mathrm{ha}^{-1}$ de mesotrione, decrescendo conforme houve a redução da dose. Durante as avaliações visuais, o sintoma mais pronunciado foi o branqueamento nas folhas ou albinismo, algumas vezes com lesões de coloração rosada ou violácea, semelhante aos sintomas descritos por Felix \& Doohan (2005) e Abit et al. (2009). Segundo Grossmann \& Ehrhardt (2007), a inibição da sintese de carotenoides causada pela ação do herbicida leva à decomposição da clorofila pela luz, como resultado da perda da fotoproteção fornecida pelos carotenoides, resultando na degradação oxidativa da clorofila e, em casos mais extremos, na oxidação das membranas celulares. Esses sintomas são característicos dos herbicidas inibidores da sintese de carotenoides.

Observou-se ligeira recuperação dos sintomas aos 28 DAA (Figura 1), sugerindo que o cultivar Marandu apresenta grande capacidade de recuperação dos efeitos supressivos provocados pelo mesotrione. Durante essa avaliação, verificou-se também que os niveis máximos de fitointoxicação chegaram a 20\% (192 $\mathrm{g} \mathrm{ha}^{-1}$ ), não sendo constatada redução na população de plantas da forrageira. Segundo Mitchell et al. (2001), a seletividade e a grande capacidade de recuperação dos sintomas causados pelos herbicidas pertencentes à família das tricetonas ocorrem em função do rápido metabolismo do herbicida, através do processo da hidroxilação. Pataky et al. (2008) observaram que a hemoproteína citocromo P-450 é a responsável por esse processo de detoxificação.

Embora os niveis de fitointoxicação tenham sido considerados baixos, ao analisar os percentuais de acúmulo da biomassa seca da parte aérea aos 28 DAA (Figura 2), constatase que as maiores reduções foram obtidas com a aplicação da maior dose de mesotrione (192 $\mathrm{g} \mathrm{ha}^{-1}$ ), indicando que os efeitos sobre a biomassa seca estão diretamente relacionados com o incremento da dose aplicada. Ainda, de acordo com os resultados obtidos, verifica-se que o mesotrione impôs baixos níveis de supressão em relação ao intervalo de doses aplicadas, o que possibilitou melhor ajuste, evitando assim os efeitos indiretos causados pela competição entre as plantas de milho/ forrageira utilizadas na integração. Para Jakelaitis et al. (2005), herbicidas como o nicosulfuron só podem ser utilizados no manejo de $B$. brizantha em doses inferiores a cinco vezes a dose comercial recomendada para a cultura do milho, já que doses superiores a $12 \mathrm{~g} \mathrm{ha}^{-1}$ causam grande redução sobre o acúmulo de matéria seca em plantas de $B$. brizantha, dificultando o estabelecimento da forrageira.

Durante a avaliação feita aos 28 DAA, verificou-se que a dose necessária para reduzir $50 \%$ da biomassa seca de $B$. brizantha foi de $108 \mathrm{~g} \mathrm{ha}^{-1}$ de mesotrione, ou seja, valores relativamente próximos da dose comercial do herbicida, que é de $120 \mathrm{~g}_{\text {ha }}^{-1}\left(0,25 \mathrm{~L}\right.$ p.c. ha- $\left.{ }^{-1}\right)$, indicando a baixa sensibilidade da espécie, facilitando assim o posicionamento sobre a cultura do milho quando se visa ao controle de plantas daninhas.

Analisando o coeficiente angular da equação de regressão que modela o controle de $D$. horizontalis presente numa densidade de 4,1 plantas $\mathrm{m}^{2}$ (Figura 3), observa-se que o mesotrione se apresentou como uma alternativa promissora $(80,03 \%$ de controle) quando utilizado na dose de $184 \mathrm{~g} \mathrm{ha}^{-1}$, chegando a 83,39\% na dose de $192 \mathrm{~g} \mathrm{ha}^{-1}$. Em doses inferiores, os niveis de controle dessa espécie foram insatisfatórios. Em contrapartida, C. echinatus $\left(2,8\right.$ plantas $\left.\mathrm{m}^{2}\right)$ não foi controlada

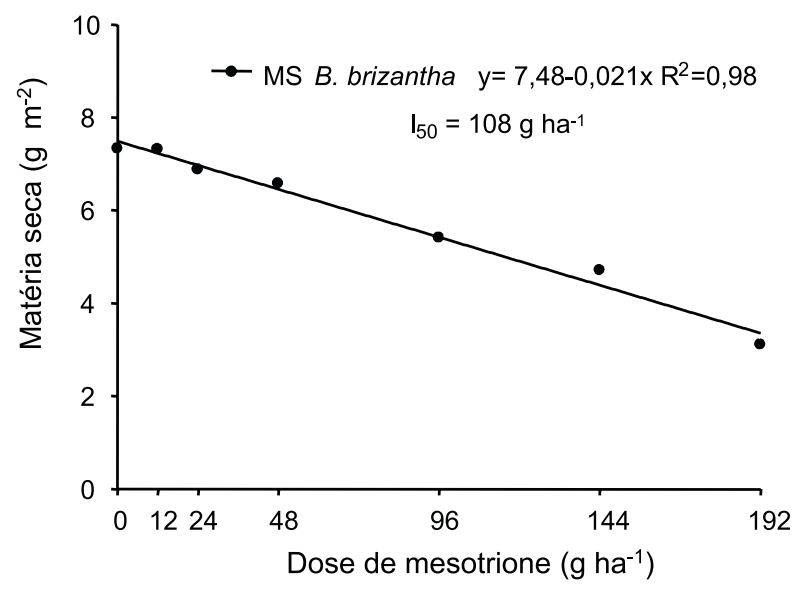

Figura 2 - Acúmulo de matéria seca na parte aérea de plantas de B. brizantha cultivada em integração com milho, aos 28 dias após a aplicação de diferentes doses de mesotrione em pósemergência. 


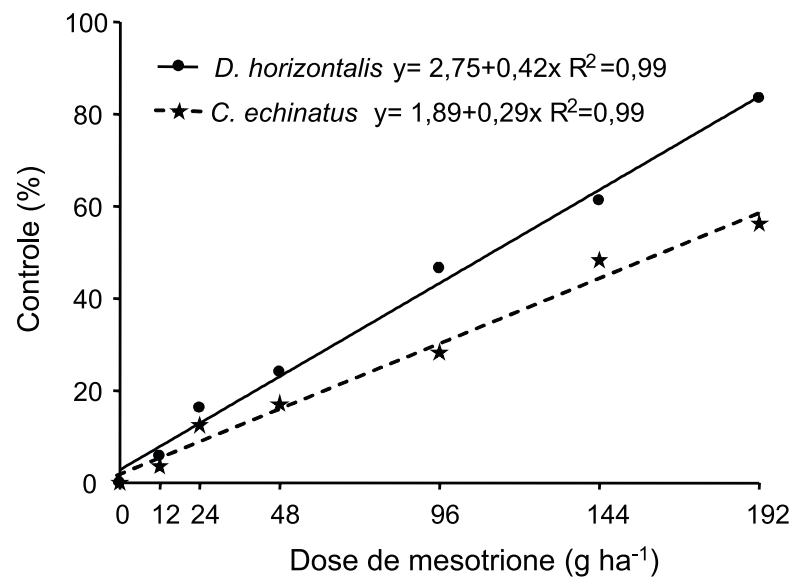

Figura 3 - Controle das plantas infestantes D. horizontalis e C. echinatus, presentes em área cultivada no sistema de integração lavoura-pecuária, aos 28 dias após a aplicação de diferentes doses de mesotrione em pós-emergência.

de forma eficiente pelo herbicida dentro do intervalo de doses estudado. Segundo Dan et al. (2011), o principal agravante é que as doses de herbicidas utilizadas para supressão da forrageira geralmente são inferiores às recomendadas para o controle das plantas daninhas, ou seja, são consideradas subdoses, facilitando assim os escapes das espécies infestantes, principalmente de gramíneas como C. echinatus - caso observado no presente ensaio. Entretanto, vale ressaltar a importância de uma dose equilibrada do herbicida, uma vez que o simples fato de suprimir as plantas daninhas poderá auxiliar no manejo cultural realizado pela forrageira - fato observado por Ceccon et al. (2010).
Quanto aos efeitos do sistema integrado sobre a cultura do milho, observa-se a importância do manejo da forrageira a fim de evitar a competição. A presença de $B$. brizantha crescendo livremente com a cultura proporcionou reduções significativas sobre as variáveis altura de inserção da primeira espiga, altura de planta e rendimento de grãos do milho, quando comparadas às do cultivo de milho solteiro (Tabela 1). Reduções ocorridas em função da competição interespecífica envolvendo as espécies em integração também foram relatadas por Gimenes et al. (2009, 2011).

Tanto a altura de planta quanto a inserção da primeira espiga deixaram de apresentar resultados negativos quando o mesotrione foi utilizado em doses a partir de 144 e $96 \mathrm{~g} \mathrm{ha}^{-1}$, respectivamente (Tabela 1). Portanto, a competição interespecífica pode ser considerada fator limitante caso não seja realizada uma intervenção com o intuito de regular o crescimento da espécie forrageira. Esses resultados corroboram os apresentados por Jakelaitis et al. (2010), ao observarem que a semeadura concomitante interferiu na altura de planta dos cultivares AG-2040 e 30F87. Não obstante, a competição entre as culturas integradas deixou de causar danos ao rendimento de grãos do milho quando o herbicida foi aplicado em doses a partir de $96 \mathrm{~g} \mathrm{ha}^{-1}$. Esse valor pode ser considerado, portanto, como o limite mínimo na definição da dose para que se realize um manejo sem interferência da forrageira na rentabilidade do milho, garantindo maior retorno econômico. Ceccon et al. (2010)

Tabela 1 - Altura de inserção da primeira espiga, altura de planta e rendimento de grãos do milho cultivado em integração com B. brizantha, após a aplicação de diferentes doses de mesotrione em pós-emergência. Rio Verde, GO. 2007/2008

\begin{tabular}{|l|c|c|c|c|}
\hline \multicolumn{1}{|c|}{ Tratamento } & Dose $\left(\mathrm{g} \mathrm{ha}^{-1}\right)$ & $\begin{array}{c}\text { Altura de inserção da } \\
\text { primeira espiga (m) }\end{array}$ & Altura de planta (m) & $\begin{array}{c}\text { Rendimento de grãos } \\
(\mathrm{kg} \mathrm{ha})\end{array}$ \\
\hline Mesotrione & 0 & $0,75 \mathrm{c}$ & $2,13 \mathrm{~d}$ & $4.792 \mathrm{~b}$ \\
\hline Mesotrione & 12 & $0,76 \mathrm{c}$ & $2,13 \mathrm{~d}$ & $4.660 \mathrm{~b}$ \\
\hline Mesotrione & 24 & $0,76 \mathrm{c}$ & $2,15 \mathrm{~d}$ & $4.982 \mathrm{~b}$ \\
\hline Mesotrione & 48 & $0,80 \mathrm{~b}$ & $2,21 \mathrm{c}$ & $5.218 \mathrm{~b}$ \\
\hline Mesotrione & 96 & $0,85 \mathrm{a}$ & $2,29 \mathrm{~b}$ & $5.581 \mathrm{a}$ \\
\hline Mesotrione & 144 & $0,87 \mathrm{a}$ & $2,32 \mathrm{a}$ & $5.556 \mathrm{a}$ \\
\hline Mesotrione & 192 & $0,86 \mathrm{a}$ & $2,35 \mathrm{a}$ & $5.922 \mathrm{a}$ \\
\hline Milho solteiro capinado & - & $0,88 \mathrm{a}$ & $2,35 \mathrm{a}$ & $5.705 \mathrm{a}$ \\
\hline
\end{tabular}

Médias seguidas pela mesma letra na coluna não diferem estatisticamente entre si pelo teste de Scott-Knot a 5\% de probabilidade. 
observaram que $60 \mathrm{~g} \mathrm{ha}^{-1}$ de mesotrione foi suficiente para evitar efeitos negativos de $B$. ruziziensis sobre o rendimento do milho em integração.

De acordo com os resultados, pode-se inferir que a utilização de mesotrione se mostra como uma ferramenta importante nos sistemas de integração lavoura-pecuária, sobretudo quando a forrageira é semeada concomitantemente com a cultura. Nesse caso, a adoção de alternativas que possam "limitar" o desenvolvimento agressivo de espécies como $B$. brizantha auxilia no manejo de plantas daninhas, sem, no entanto, limitar a posterior formação da pastagem, posicionandose de forma adequada nessas situações.

Com relação ao rendimento total de biomassa seca de $B$. brizantha estimada no momento da colheita do milho (120 dias após a semeadura), os resultados indicam que o herbicida em doses a partir de $144 \mathrm{~g}^{\text {ha }}{ }^{-1}$ alterou significativamente o rendimento final de forragem (Tabela 2). Por outro lado, doses inferiores a $96 \mathrm{~g} \mathrm{ha}^{-1}$ de mesotrione não influenciaram o acúmulo de biomassa seca de $B$. brizantha, demonstrando a capacidade que a espécie apresenta de recuperação dos efeitos causados pelo herbicida. Vale ressaltar que essa capacidade é decorrente de diversos fatores, entre os quais se destacam o espaçamento entre linhas, o tipo de semeadura, a arquitetura foliar do híbrido de milho e as condições edafoclimáticas da região (Jakelaitis et al., 2010).

Tabela 2 - Matéria seca da parte aérea de plantas de B. brizantha no momento da colheita da cultura do milho cultivado em integração. Rio Verde-GO. 2007/2008

\begin{tabular}{|l|c|c|}
\hline \multicolumn{1}{|c|}{ Tratamento } & $\begin{array}{c}\text { Dose } \\
\left(\mathrm{g} \mathrm{ha}^{-1}\right)\end{array}$ & $\begin{array}{c}\text { Matéria seca } \\
\left(\mathrm{kg} \mathrm{ha}^{-1}\right)\end{array}$ \\
\hline Mesotrione & 0 & $975 \mathrm{~b}$ \\
\hline Mesotrione & 12 & $980 \mathrm{~b}$ \\
\hline Mesotrione & 24 & $910 \mathrm{~b}$ \\
\hline Mesotrione & 48 & $882 \mathrm{~b}$ \\
\hline Mesotrione & 96 & $845 \mathrm{~b}$ \\
\hline Mesotrione & 144 & $775 \mathrm{c}$ \\
\hline Mesotrione & 192 & $692 \mathrm{c}$ \\
\hline Braquiária solteira capinada & - & $4.693 \mathrm{a}$ \\
\hline \multicolumn{1}{|c|}{ CV (\%) } & & 11,27 \\
\hline
\end{tabular}

Médias seguidas pela mesma letra na coluna não diferem estatisticamente entre si pelo teste de Scott-Knot a $5 \%$ de probabilidade.
Em sintese, a dose de $96 \mathrm{~g} \mathrm{ha}^{-1} \mathrm{de}$ mesotrione pode ser considerada o ponto de equilíbrio entre a máxima produção de grãos do híbrido de milho DKB 789 e os mínimos níveis de injúria causados na espécie forrageira em estudo.

Brachiaria brizantha apresenta tolerância satisfatória ao mesotrione, o que demonstra o potencial de utilização desse herbicida em sistemas de integração lavoura-pecuária envolvendo essa forrageira e a cultura do mi1ho. A dose de $96 \mathrm{~g} \mathrm{ha}^{-1}$ de mesotrione apresenta a melhor relação dose-benefício para as espécies em integração milho e Brachiaria brizantha.

\section{LITERATURA CITADA}

ABIT, M. J. M. et al. Differential response of grain sorghum hybrids to foliar-applied mesotrione. Weed Technol., v. 23, n. 4, p. 28-33, 2009

CECCON, G. et al. Uso de herbicidas no consórcio de milho safrinha com Brachiaria ruziziensis. Planta Daninha, v. 28, n. 2, p. 359-364, 2010.

FELIX, J.; DOOHAN, D. J. Response of five vegetables crops to isoxaflutole soil residues. Weed Technol., v. 19, n. 1, p. 391-396, 2005.

FERREIRA, L. R. et al. Formação de pastagem em sistema de integração. Inf. Agropec., v. 28, n. 240, p. 52-62, 2007.

FREITAS, F. C. L. et al. Formação de pastagem via consórcio de Brachiaria brizantha com o milho para silagem no sistema de plantio direto. Planta Daninha, v. 23, n. 1, p. 49-58, 2005.

GIMENES, M. J. et al. Integração Lavoura-Pecuária - Breve revisão. R. Trópica, v. 4, n. 1, p. 52-67, 2009.

GIMENES, M. J. Interferência da Brachiaria decumbens stapf. sobre plantas daninhas em sistema de consórcio com o milho. Revista Caatinga, v. 24, n. 3, p. 215-220, 2011.

GROSSMANN, K.; EHRHARDT, T. On the mechanism of action and selectivity of the corn herbicide topramezone: a new inhibitor of 4- hydroxyphenylpyruvate dioxygenase. Pest Manag. Sci., v. 63, n. 1, p. 429-439, 2007.

DAN, H. A. et al. Supressão imposta pelo atrazine a Digitaria horizontalis em função do estádio de desenvolvimento. Revista Caatinga, v. 24, n. 1, p.27-33, 2011. 
JAKELAITIS, A. et al. Efeitos de herbicidas no consórcio de milho com Brachiaria brizantha. Planta Daninha, v. 23, n. 1, p. 69-78, 2005

JAKELAITIS, A. et al. Efeitos de herbicidas no controle de plantas daninhas, crescimento e produção de milho e Brachiaria brizantha em consórcio. Pesq. Agropec. Tropical, v. 36, n. 1, p. 53-60, 2006.

JAKELAITIS, A. et al. Cultivares de milho e de gramíneas forrageiras sob monocultivo e consorciação. Pesq. Agropec. Tropical, v. 40, n. 4, p. 380-387, 2010.

MACHADO, L. A. Z.; ASSIS, P. G. G. Produção de palha e forragem por espécies anuais e perenes em sucessão à soja.

Pesq. Agropec. Bras., v. 45, n. 4, p. 415-422, 2010.

MACEDO, M. C. M. Integração lavoura e pecuária: o estado da arte e inovações tecnológicas. R. Bras. Zootec., v. 38, n.2, p. 133-146, 2009.

MITCHELL, G. D. W. et al. Mesotrione: A new selective herbicide for use in maize. Pest Manag. Sci., v. 57, n. 3, p. 120-128, 2001.
PACHECO, L. P. et al. Desempenho de plantas de cobertura em sobressemeadura na cultura da soja. Pesq. Agropec. Bras. v. 43, n. 3 , p. $815-823,2008$

PATAKY, J. K. et al. Genetic basis for varied levels of injury to sweet corn hybrids from three cytochrome P450metabolized herbicides. J. Am. Soc. Hortic. Sci., v. 133, n. 2, p. 438-447, 2008.

PORTES, T. A. et al. Análise do crescimento de uma cultivar de braquiária em cultivo solteiro e consorciado com cereais Pesq. Agropec. Bras., v. 35, n. 7, p. 1349-1358, 2000.

TIMOSSI, P. C. Manejo de rebrotes de Digitaria insularis no plantio direto de milho. Planta Daninha, v. 27, n. 1, p. $175-179,2009$.

TORRES, J. L. R.; PEREIRA, M. G.; FABIAN, A. J. Produção de fitomassa por plantas de cobertura e mineralização de seus resíduos em plantio direto. Pesq. Agropec. Bras., v. 43, n. 3, p. 421-428, 2008. 